\title{
Peer Teachers' Online Learning Community for Diversified College English Teaching Research: Cooperation and Contribution
}

\author{
Li Wei \\ Liaoning Police Academy, Dalian, China
}

\begin{abstract}
Network English teaching research has attracted the attention of many college English teachers who are keen on the application of information technology and the seamless communication between teaching and learning participants since network technology was applied into foreign language teaching. The article introduces an online learning community titled Sharing \& Improving among inter-college English teachers and excellent college students with the main focus on creating a communicative platform to discuss the hot issues concerning English education, and to explore those English teaching and learning problems troubling teachers and students. This is a platform advocating the equal and open dialogue between community members regardless of experts, teachers, and students. This is also a diversified and interactive stage promoting multi-dimension assessment mechanism in college English writing and multi-level discussion mechanism in English teaching research. After 6-month-research, this online learning community not only fulfils software of Four-dimension College English Writing Assessment Models, but also conducts a series of academic discussions concerning English teaching prospects and strategies. Those college students become very sensitive to English through constant training in English communication and discussion, thus promoting their comprehensive development in English skills. Ultimately, all the community members realize their initial goal to achieve the common progress in humanistic qualities by means of experiential and interactive learning in English.
\end{abstract}

Index Terms - peer teacher, online learning community, college English teaching and research

\section{INTRODUCTION}

Confronted with the problems caused by the college English teaching reforms, the front-line English teachers often run across many puzzles, reflecting on their regular teaching practice at the same time. As more and more information technology entering into our foreign language teaching and research, English teachers commence to explore the principles and practice of the network teaching and research. The Chinese internet has been swept by a "Blog whirlwind" since 2006, hence a lot of well-known education blogs and resources websites came into the sights of teacher's community. Some English teachers made full use of this latest network platform to share their own teaching plans, videos, software, and even reflections, which became a popular way of sharing in individual research achievements. With the wide use and recognition of the network teaching and research, a vast majority of English teachers engage in network teaching through setting up online learning community to construct a new world of personal voice cyberspace on their own.

At the moment, many experts and scholars turn their attentions to this new pattern of teaching research, drawing a timely conclusion on its rules, methods, patterns as well as strategies. For instance, they tend to believe that the traditional teaching activities are confined to the space range and the financial support leading to the limited number of participants and face-to-face instruction featured by entering into the spot and conducting collective instilment. Fortunately, the network teaching research has the great advantages over the traditional one with such characteristics as low participation costs, wide range of participants, abundant resource sources, higher-leveled sharing, and flexible organizational patterns. Under such online learning community on the basis of learning interests, teaching subjects and common goals, the community members can convey their own voices and strong desires for sharing experiences and improve themselves accordingly. (Gong, 2008) Till now, there have been three kinds of network teaching research including self-reflection based on blog, cooperative research based on forum, and resources sharing and editing based on subject resources websites. (Li, 2007) For any kind of research pattern, it always demonstrates the following features: the teacher basis, peer cooperation, and major guidance. Up to now, the space to meet the needs of network teaching researchers has been set up, hence the network teaching research turned from the initial stage of platform construction to the critical stage of exploring the operational mechanism. This article focuses on the diversified operation mechanism of an online learning community for inter-college English teachers by means of various forms and perspectives of demonstration and performance of peer teacher's interactions, discussions and presentations through on-the-spot network teaching research. 


\section{Theoretical Exploration of Diversified Teaching ConcePt And PeER Teachers’ OnLine Learning COMMUNITY}

\section{A. The Analysis of Diversified Teaching Concept and Its Significance}

The concept diversification is a comprehensive one which can describe the diversified characteristic of any creatures in the world. Diversification is a kind of objective existence. Any creature living in the world is existed as an objective subject regardless of genetic diversification in biology, cultural diversification in social lives, or students' individuality and learning environment diversification in education. (Ren, 2010) Diversification is an ultimate goal put forward by education field. In ancient times in China, some educators advanced the basic educational principle of teaching according to different talents which emphasized that the teachers should teacher the students in different ways in accordance with their practical conditions and individual differences. This traditional teaching principle can match with diversified teaching concept of today. But due to the present teaching system, the enlarged number of classmates and the limited teaching resources, to perform diversified teaching is nothing more than a beautiful teaching ideal. If fact, diversified teaching is the highest goal in our education, and at the same time, it's a practical concept which refers to the curriculum practice and development. The ultimate goal of our education reform is to increase teaching efficiency and teaching quality, contributing to the students' all-round development. Only adopting diversified teaching methods, teaching materials, teaching objectives, and teaching organizations can our education system adjust to the force of international competitions and the requirements of different learners. As the network teaching research, online learning community members have to practice the diversified teaching concept through setting up a complete network teaching research community in the form of diversified and cooperative teaching coordination. They can conduct multiperspective teaching discussion, teaching practice, and teaching reflection among all the community members by means of service mechanism, cooperative pattern, assessment and encouragement mechanism.

\section{B. The Analysis of Peer Teacher's Concept and Its Cooperative Learning Functions}

Peer, in Chinese dictionary, means fellows of the same generation with the similar age, status and interests. Peer teachers refer to the teachers with the same major, subject background, and inclinations without limitations of age, status and identity. Here, on one hand, the connotation of peer is extended to that of colleague which reflects that they can help each other holding the common faith persistently, and on the other hand, the peer relation breaks through the serious restriction which make peer relation have the nature of colleague relation and inter-college teacher relation. In view of this tendency, it is believed that peer teachers' teaching and learning can help create a relative easy atmosphere to make professional dialogues with feedbacks and reflections. Peer teachers can interact with each other in a more free and natural way to find a commonly-interested topic which improves their learning motives and self-confidence, developing their critical thinking abilities to resolve the problems, and their responsible efforts to fulfill learning tasks. (Tsuei, 2011) From Topping's points of view, there are five interactive types of peer teacher's learning: peer tutoring, peer modeling, peer monitoring, peer assessment, and peer counseling as well. (Topping, 2001)

\section{The Organization of Inter-college Online Learning Community and Its Distant Cooperation}

An organization has to possess the particular members, amount, sphere, structure, rules and values. (Chang, 2005) Wenger, as the first person to invent practical community, upholds that the practical community requires that the organizing form acknowledges the significance of passion, relation, and volunteer activities. The core concept of intercollege online learning community is to make more and more members to participate into the learning and developing process of online learning community willingly. In general, inter-college online learning community is composed of inter-college teachers, learning assistants, students, and experts. These community members have the common ideals and the same learning objectives because of inter-college curriculum cooperation and teaching exploration. Teachers are the main organizers to initiate inter-college cooperation; they usually have three functions: to design and organize the students to learn before constructing the online learning community and in the process of its operation; to design and promote dialogues among all the community members including students, teachers, and experts as well; to conduct various learning guidance. (Anderson \& Elloumi, 2013) Telementoring is the nature of online learning community. Under this kind of leaning pattern, the experienced guide and young beginners share relative knowledge and skills in order to help beginners achieve their learning goals or improve their learning abilities. (Wang, 2003) In the process of inter-college cooperation, teachers' covert and overt teaching experiences and professional knowledge are highly shared by community members from various colleges so as to inspire and promote peer teachers' intelligence which not only contributes to the multiple and complementary elements in inter-college cooperative teaching, but also constitutes the key point to construct inter-college peer teachers' learning team.

\section{Organizational Strategies and Application of InTER-COLlEge Collaborative OnLine Learning COMMUNITY FOR COLLEGE ENGLish TEACHERS AND STUDENTS}

\section{A. The Logic and Organizational Strategies of Inter-college Online Learning Community}


In the perspective of differentiated cooperation, the logic of inter-college cooperation is the individual differentiation among different colleges. The most direct approach to realize individual development and create educational speciality is to conduct multiple teaching practice and exploration. This kind of approach is typical of diversity in teaching objectives, curriculum, resources, teaching activities and assessment as well. The front-line teachers is the main body who design their own teaching methods and strategies on the basis of mutual learning and assessment, reflection on others' experiences and specialities in order to achieve the success in training the talents with diverse abilities. Admittedly, network teaching research mechanism provides a platform for sharing resources and experiences. What's more, teachers from various regions can learn a lot and get revelation from other teachers' achievements, and thus, they can design unique teaching plans out of their own thinking and teaching experiences.

Online learning community members should be driven by the common ideals to construct an inter-college cooperative mechanism. To have the general recognition among members is the fundamental element to collect the group power. At the same time, the coordinator management mechanism should be used to permit the existence of different cultures, organizations and interests deriving from different colleges. The coordinator is responsible for developing the core members in the community through a period of observation and interaction. To search for the suitable cooperative fellows and develop multi-levelled inter-college virtual team is the second task of coordinator. There are three types of virtual inter-college teams including students' inter-college cooperative team focusing on research study or comprehensive project development; theme-based inter-college cooperative team focusing on theoretical research or case study; whole class inter-college cooperative team focusing on network communication instead of task assignment. ( $\mathrm{Li}, 2013)$

\section{B. The Organizational Design of Inter-college Collaborative Online Learning Community}

The author launched a proposal to set up an online leanring community among college English teachers with its main component coming from Liaoning Police Academy in October, 2013.This online learning community is entitled with Sharing \& Improving underlining resources sharing in English study and keep improving in inquiring spirits. It is composed of three organizaitonal elements: the organization of community members, the setting of ideals and objectives, and the operation of coordinator mechanism. In order to embody the features of inter-college collabration and equal dialogue among teachers and students, the author specially invited 7 outstanding college English teachers and 36 excellent college students from 7 universities and colleges to join this online learning community. These universities include Liaoning Normal University, Nanjing Normal University, Bohai University, Liaoning Engineering and Technology University, Chuxiong Normal University, Dalian Mediacal University, and Liaoning Police Academy. At the same time, the community has set up definite ideals and objectives which include fufilling inter-college English teaching collabration and exchanges through network interaction about English teaching approaches, effects and assessments, realizing inter-college students' mutual studying and simulating through reading others' online products, discussing English learning techniques, and resolving English problems together, and promoting the common improvement in humanistic qualities among all the community members. In the process of iner-college cooperation, teacher coordinators mainly finish the following tasks: to design inter-college cooperative projects; to guide the students in their universities to conduct iner-college distant collaboration; to take part in mentoring inter-college coorpration. Student coordinators usually take charge of inter-college students' interactive activities which include making arrangements for regular interactive topics, schedules of regular activities, and resolving the communicative problems. Figure 2 presents us the framework of organizational design of inter-college collaborative online leanring community.

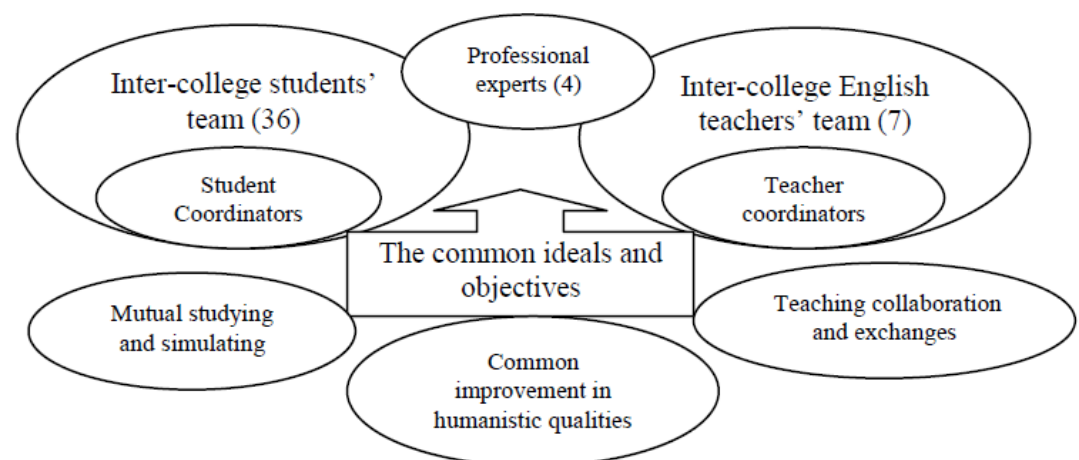

Figure 1: The organizational design of inter-college collaborative online learning community.

\section{The Deversified Operational Mechanism of Inter-college Collaborative Online Learning Community}

Construction of diversified assessment mechanism in college English writing: In Sharing \& Improving, there are four-leveled writing assessments: self-assessment, peer assessment, teacher's assessment, public assessment. All the student members upload their compositions after self-assessment and peer assessment to the group sharing, English teachers in community will give very serious and cautious assessment and revision. Till now, the group sharing has 
stored fifty excellent compositions. Figure 2 is the screenshot of these uploaded compositions in group sharing and in chat room.

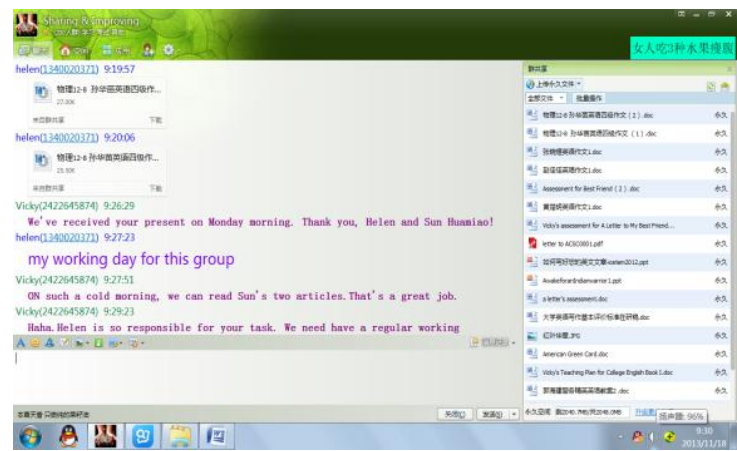

Figure 2: English teacher Helen is uploading two assessed compositions by her to the group sharing.

The following is the assessment model made by the author, the group leader Vicky. This letter is written by one of his students, a freshman majoring in criminal science technology. After his self-assessment and peer assessment, Han Gang uploaded his writing to group sharing for his English teacher's assessment.

A Letter to My Best Friend

Written by Han Gang, Assessed by Vicky

(Criminal Science Technology Department, Class 2 Grade 2013)

Dear Ma,

How is going?

Although we often keep up correspondence, I still miss you very much. One day, (when) I watched TV at home, (;) suddenly I saw the TV play is old (I saw an old TV play). (, which) It (it can be replaced by which) reminded me of the time with you. At that time, we were young.

(Comment: to use the greetings as the beginning of the letter is very common, but you'd better use how everything is, or how you are doing to replace your "how is going". Besides, the second paragraph can be combined with the greeting to make the first paragraph rich and complete. It's a good attempt to use a TV play to introduce the beautiful time you spent with your best friend. )

When we were children, we played games together every day, and it remained (left) us wonderful (memories of) childhood (or it remained in our cherished childhood memories). The beautiful memory (Those beautiful memories) reawakes (reawake) in my mind every now and then. (This is a good sentence using reawake and every now and then.)

(Comment: this short paragraph can be regarded as a transitional paragraph leading to the main part of this letter.)

Time goes by, (;) we both grow up. (Today) You and me (I) have (our) dreams to come true, So (so) we are (have to) struggle at (for) our career.

(Comment: this is a faulty part. There are many errors in this paragraph including punctuation mark and the usage of the pronoun, the capitalized word and the preposition as well. The last sentence is a wrong one. What's more, this paragraph doesn't have close connection with the previous one. You'd better recall the beautiful times you spent with your friend instead of using this sentence without detailed descriptions about your friendship. This sentence can be put in the latter part.)

Do you remember those things (beautiful or funny days) the (that) we had spended (spent)? Aha, you copy (copied) my homework all the way because you aren't (weren't) much of a hand at doing homework. Beside(s) I said that there is a will, there is a way. (This sentence hasn't step-up relationship with the previous one, so it should be changed or deleted. You can change it to "But I always encouraged him to work hard at his school work by telling him that there is a will, there is a way.) When we had done homework (After finishing our homework), we hung out (on) the same corner, or I rode bike and you settled into the back seat (to see the sunset together). What's more, we climbed the trees to pull out the bird's nest (to take eggs from the bird's nest), or went to a river to catch frogs. Every time (we spent together), we both had a good time (a great ball). Now, (come to think of it), I think of (delete) it's really exciting, (such an unforgettable memory.) and it's a fine memory (delete it).

(Comment: This paragraph is the main body of this letter which describes the good old days these two friends spent together in a very vivid way. It tells us his friend is a little lazy copying his pal's homework. Both of them are very naughty and lovely who take eggs from the nest and catch frogs. In a word, they have wonderful childhood with two friends helping each other and enjoying their favorite hobbies. But you'd better avoid some errors in verb tense and logical relationship between two sentences. Besides, you should try to use some beautiful words and sentence structures to brighten your essay.)

Last but not least, I only (do) hope that we don't (won't) lose touch (with) each other. Best wish (es) to you--------my old neighborhood (pal). Please keeping (keep or stay) (yourself) healthy (and happiness) in the distance. 
(Comment: This is the closing remark for this letter. You express your hope to keep in touch with each other and good wishes to keep healthy. Good job! Here, you have to pay attention to some minor mistakes, and you'd better add some expressions to bring about your friend's emotional response.)

Take care.

Yours,

Han Gang

The final comment: The article can keep to the subject of Best Friend expressing the deep love that the author has for his best friend; the content is intact but not very rich; the expression of ideas is relatively clear in setting out his points of views and arguments; the language performance is basically correct but with some grammatical and spelling errors; the structure of the article is basically reasonable with clear levels and coherent meanings, but some coherence isn't very natural; the writing of this article is rather standard in format and number of words which achieves the communicative purposes. The final score is 78 (the full score is 100).

Construction of diversified communication and discussion mechanism in English teaching research: Sharing \& Improving is an equal platform for communication and discussion regardless of teachers and students. The students' voices are paid great attention in this learning community because they determine the ultimate effects and directions of English teaching. Without student's participation and voices, the English teaching research will be meaningless and ineffective. In Sharing \& Improving, the fundamental principle is that every community member is equal in communication and discussion with anonymous English names so that there is no differentiation between teacher and student. And they can communicate with each other equally and actively concerning educational issues or English learning and development problems. Figure 3 and Figure 4 display the real experiences of this communication. And the detailed recordings of each communication from QQ information come as follows. In this learning community, the concept of equality and democracy has been interpreted totally and vividly.

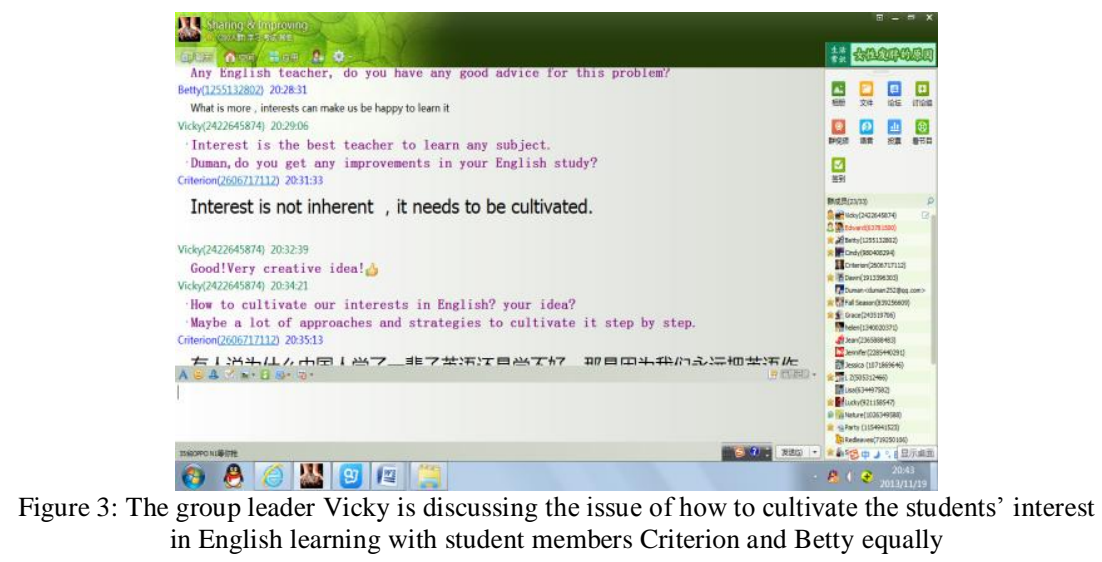

2013-11-19

Vicky (2422645874) 20:19:07

Now Let's discuss a hot issue: How to maintain the students' passion for English learning if without CET4 or CET6? I'm looking forward to your unique points of views or suggestions.

Criterion(2606717112) 20:19:57

good topic

Betty(1255132802) 20:22:29(a freshman)

Teacher,1 like studying English from the bottom of heart,because 1 think it is relaxing to study in your teaching man ner.

Vicky (2422645874) 20:23:42

First of all,we should unify our understanding that the goal of learning English is not to pass any kind of exam includ ing TOEFL, GRE,CET4 and CET6.

Yeah, I agree with your point of view. To learn something out of your interests and passion can make you learn effectively and easily.

Vicky (2422645874) 20:25:45

Only by this active way of learning can you learn it with great efforts, and of course, with great benefits.

Vicky (2422645874) 20:27:31

Any English teacher, do you have any good advice for this problem?

Betty (1255132802) 20:28:31

What is more, interests can make us happy to learn it

Vicky (2422645874) 20:29:06

Interest is the best teacher to learn any subject.

Duman (a minority junior), do you get any improvements in your English study? 
Criterion (2606717112) 20:31:33(a junior)

Interest is not inherent, it needs to be cultivated.

Vicky (2422645874) 20:32:39

Good! Very creative idea!

Vicky (2422645874) 20:34:21

How to cultivate our interests in English? Your idea?

Maybe there are a lot of approaches and strategies to cultivate it step by step.

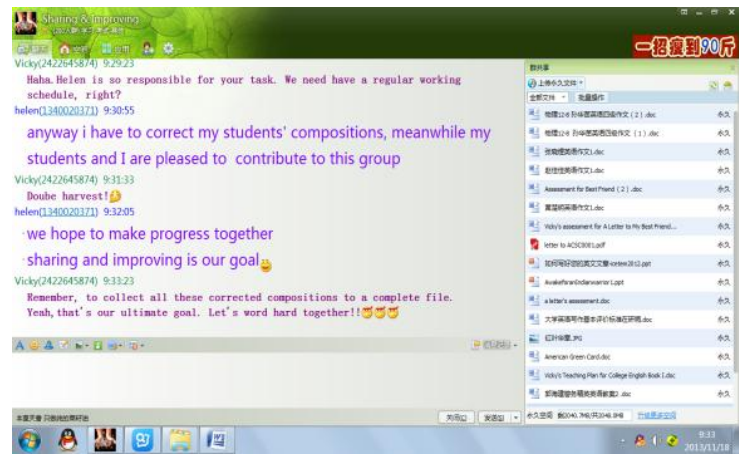

Figure 4: The group leader Vicky is discussing with Helen, an English teacher in Bohai University on the issue of how to inspire students' desire for English in big class more than 60 students.

2013-10-24

Vicky (2422645874) 13:55:18

The establishment of this group not only aims to hold routine English teaching activities and carry on English teachin $\mathrm{g}$ research, but also lends those students passing CET4, CET6, or postgraduate entrance exam a good hand to fulfil the task of deep-levelled learning.

Vicky (2422645874) 14:21:02

English teaching and learning is an interactive process, teaching can be inspired by learner's desires and questions, an $\mathrm{d}$ learning can be encouraged and improved by teaching.

Jean(2365888483) 17:34:28 (an English teacher in Liaoning Police Academy majoring in English Literature) Iagree with you.I'm encouraged and improved by my teaching now,especially for my writing.I enjoy it very much.By th e way,thank you very much for your precious advice!

Helen (1340020371) 19:45:50

I'm not teaching the English major. We hardly have any discussion in class. Firstly, the class is so big, at least 60 .

Secondly, students are reluctant to speak English although I ask them in English. Thirdly, in order to pass the CET4/6, students have to learn English in the way it is examined.In a word, it is really a headache for me to inspire the students $t$ o SPEAK!

Vicky (2422645874) 19:54:12

Helen, I can understand your difficult condition! Anyway, don't be in despair! If you have some class with no more than 40 students someday in the future, you'll display your talent to inspire your students to speak English, to put forward their points of views in English very actively. But for 60 students, it's really a problem. How to improve students' speaking skills in such a big class; this is a good question to probe into. Give us solutions, my dear colleagues!

Vicky (2422645874) 20:00:30

How to inspire your students to speak English in a big class more than 60 students?

This is our first topic to discuss, and anybody in this group can contribute your creative ideas!

2013-10-25

Jessica (1071869646) 9:25:59

As to this question, you can change the mind that a small class has a perfect listening and study atmosphere,and teach them in a big class, let them sit alone aiming to divert the students' attention and make them relaxed.

Helen (1340020371) 9:29:27

Thank you. Sit alone? You mean sit separately?

Helen (1340020371) 9:29:36

No partner?

Jessica (1071869646) 9:29:55

Yes.

Helen (1340020371) 9:32:10

Oh, perhaps it won't work because of the seating capacity of the classroom. 
Jessica (1071869646) 9:32:32

They can't communicate.

Helen (1340020371) 9:33:09

The students prefer to communicate on their phones.

Helen (1340020371) 9:33:35

It can be applied to some students.

Jessica (1071869646) 9:34:36

You can build a micro message.

Helen (1340020371) 9:34:40

There are always a few who choose to sit by themselves

Jessica (1071869646) 9:38:02

Speak more and they have confidence

Vicky (2422645874) 9:38:38

Jessica is good at English learning. Sit with partner or sit alone, it doesn't influence her attention to English teaching.

But for those with lower interests in English, they should have a better learning atmosphere. They can have a partner who loves English very much to give them positive influence. Am I right?

Helen (1340020371) 9:39:37

Our teaching aim?

Helen (1340020371) 9:39:53

Pass the tests or improve oral English? Or simply arouse the students' interests?

Helen (1340020371) 9:40:34

The measurements?

Vicky (2422645874) 9:42:45

Learning interests is the premise to learn well.

And teaching aim of English is to develop students' English skills in five areas. Not only to pass CET or oral English tests only.

Jessica (1071869646) 9:44:41

I cannot agree more.

Helen (1340020371) 9:44:58

Aims, means, how to measure your experiment, the CET?

Vicky (2422645874) 9:45:36

Oral English is one part of English output, which is to display how they can speak English freely and correctly.

They also have to improve their listening, reading, and writing abilities. But all these abilities' further development should be based on initial interest in English and abundant training programs.

\section{CONCLUSIONS}

Network English teaching and research, as a new type of research approach, has become a mega trend among college English teachers. The author and her project team members depend on network platform and cloud computing technology to conduct a series of English teaching researches into educational issues, English teaching strategies, English learning problems, and hot issues as well. They create Sharing \& Improving, an equal and active online learning community, to realize the general goal of promoting common improvement in humanistic qualities among inter-college English peer teachers and excellent college students. The basic principle of this learning community is equality and open dialogue between teachers and students who can discuss any problem concerning English and education freely and equally. The basic operational mechanism is diversified cooperation and contribution which mainly include diversified assessment mechanism in college English writing, and diversified communication and discussion mechanism in English teaching research. The results of this research prove that network English teaching research can obtain the great harvest through collaborative interactions among inter-college English teachers and college students who engage in communication with other members to explore the answers of the latest English teaching and learning problems, establishing constant and stable interactive mechanism to promote the in-depth development of English teaching research.

\section{ACKNOWLEDGMENT}

The research is financed by the Twelfth Five-year Plan for Educational Science Project of Liaoning Province (2013) No. JG13EB053: On the Operation Mechanism of ESP Teachers' Online Learning Community, by Foreign Language Reform Project of Liaoning Higher Education Academy of Liaoning Province (2013) No. WYYB13177: A Study of Online Four-dimension Assessment Mechanism and Training Approach of College English Writing, and also by Teaching Research Project of Liaoning Police Academy (2013): A Study of the Multi-pattern EGP Teaching Research Based upon Cloud Technology. 


\section{REFERENCES}

[1] Chang Jinfang. (2005). Introduction of network philosophy: the reform of human's way of life in network era. Guangzhou: Guangdong people's press.

[2] Gong Daomin. (2008). Research on the pattern and practice of conducting network regional teaching research. Distance Education in China: (3) 57-60.

[3] Li Cuibai. (2013). The Organizational Strategy of Interscholastic Collaborative Online Learning Community. China Education Technology, (10): 47-50.

[4] Li Yi. (2007). Network teaching research observation for teachers' professional development in elementary education. Information Technology Education in Primary and Secondary Schools: (5) 9-12.

[5] Ren Yingjie. (2010). Inspection and reflection on interschool collaborative teaching research on the basis of differences. China Educational Technology: (12) 105-109.

[6] Terry Anderson \& Fathi Elloumi. (2013). Theory and Practice of Online Learning. (DB/OL) http://cde.athabascau.ca/online book, 2013-07-20.

[7] Topping K. (2001). Peer Assisted Learning: A practical guide for teachers. Cambridge, MA: Books.

[8] Tsuei, M. (2011). Development of a peer-assisted learning strategy in computer-supported collaborative learning environments for elementary school students. British Journal of Educational Technology, 42 (2):214-232.

[9] Wang Xia. (2003). The System of Development of Research Study. Shanghai: Shanghai Educational Publishing House.

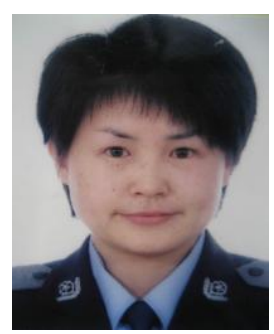

Li Wei, born in Feb. 1972 in Liaoyang, China. BA of English, Liaoning Normal University, 1993, Master of English, Liaoning Normal University, 2007. She is a professor in Liaoning Police Academy, the author of one EI indexed paper. She has published more than 40 papers in Chinese academic journals including World Ethno-national Studies, Shandong Social Sciences, Social Sciences in Xinjiang, Academy, and 20 English papers published in international journals and international conference proceedings. Her concentration centers around the Multicultural education, the Canadian Studies and network assisted Foreign Language Teaching.

Professor Wei is a candidate for the Police Liaison Officers of the Public Security Ministry of China. 